\section{Computers for Research}

Is a written answer in the House of Commons on December 21, the Secretary of State for Education and Science, Mr. A. Crosland, stated that he had invited the Council for Scientific Policy and the University Grants Committee to set up a Working Group to undertake a full-scale review of the computer requirements of universities and Research Councils, which would lead to a new 5-year programme of procurement. The Working Group, of which Prof. B. H. Flowers was chairman, reported in July, and its proposals are designed to meet the growing need for digital computing facilities for research. The Group recommended that there should be regional computing centres at the Universities of London, Manchester and Edinburgh, with very large computers to which research workers from other universities and research institutions would have access. It recommends better computing facilities for individual universities and research establishments which would be compatible with the proposed regional computers, and the system would thus form an integrated whole. At present prices, implementing these proposals for new machines, equipment, buildings and extra operating staff is estimated to cost $£ 20.5$ million for universities and $£ 9.3$ million for Research Councils in 5 years, compared with an average rate of approved orders for computers from universities over the past 3 years of less than $£ 500,000$ a year $(£ 1.2$ million in 1964). The Government has approved generally the proposals of the Group, but it is proposed to implement the programme over 6 years instead of 5 . In the first 3 years expenditure will be at the rate of about $£ 3$ million a year and orders will be placed as soon as possible. Most of the recommendations of the Group for Research Councils had high priority within the programmes of the Councils. Mr. Crosland added that he proposed to set up, in consultation with the University Grants Committee and the Council for Scientific Policy, a Computer Board, which would keep the programme under review and be responsible for ensuring the full utilization of the facilities provided in both the centres and the universities generally. The programme formed part of the plans announced by the Minister of Technology for developing the use of computers as an instrument of modernization and of economic advance. The success of this plan called for a wider use of computers in universities so that many more graduates could become aware of the capabilities of computers and be trained in their use.

\section{University of the Air}

Is a written answer to a question in the House of Commons on December 21 asking the Secretary of State for Education and Science for his plans for founding a 'university of the air', Miss Jennie Lee, Joint UnderSecretary of State for Education and Science, stated that a university of the air would provide opportunities for obtaining degrees and other technical and professional qualifications through special television and radio programmes, reinforced by correspondence courses, residential courses, and tutorial groups. It would have its own administrative centre, but would utilize existing organizations, such as local education authorities, universities and the broadcasting authorities. Costs, channels and other implications were now being considered by the Government.

\section{Mass Spectrometry Data Centre for Aldermaston}

The United Kingdom Atomic Energy Authority, with support from the Office of Scientific and Technical Information, is to set up a mass spectrometry data centre at the Atomic Weapons Research Establishment, Aldermaston. The centre will undertake an investigation into the use of computers for chemical analysis by matching and evaluating mass spectra, which will start immediately. In a 6-month research period, different matching tech- niques will be tried in conjunction with the relevant computer programmes to find the most suitable system. Another investigation which will start immediately will be into modern methods of classifying and handling information with the view of producing a spectra reference and retrieval system. This should produce a method of quickly recognizing compounds from their spectra. During the course of 1966 a world-wide index to compounds and materials already examined by mass spectrometry will be developed. For a given compound or material the index will give information such as where to find its spectrum and possibly a bibliography, its molecular weight and molecular formula. A mass spectra holding and information service will also be developed during the coming year. These last two services will, in due course, become available to mass spectrometry users throughout the world. Aldermaston has one of the largest mass spectrometry units in Britain, together with advanced computing and information facilities, which will contribute to the establishment of this mass spectrometry data centre.

\section{Royal College of Science : Research Report}

'THE Research Report of the Royal College of Science, 1962-65, summarizes the main lines of scientific research in progress during the past 3 years in the seven departments of botany and plant technology, chemistry, history of science and technology, mathematies, meteorology, physics, zoology and applied entomology (Pp. 87. London: Imperial College of Science and Technology, University of London, 1965). Emphasis is laid on the increasing cost of research brought about by use of specialized and often costly instruments. There are no references to published work. (The Royal College of Science is one of the three constituent institutions of the Imperial College of Science and Technology: the other two being the Royal School of Mines and the City and Guilds College.)

\section{Research and Development in the Electronics Industry}

THE main feature of The National Institute Economic Review (No. 34; November 1965) is a long article on research and development in the electronic capital goods industry, with substantial appendixes on sources and methods, statistical tables, references and lists of firms, organizations and individuals who assisted in the enquiry. Although the industry is one of the most labour-intensive, with a high ratio of fixed assets per man, about 60 per cent of world exports of electronic capital goods are from the United States, compared with 20 per cent from world exports of all types. This lead is attributed less to original inventions than to more rapid development of greatly improved models and more efficient technical service and marketing. The effect of the enormous scale of the military and space research and development programmes on this United States lead is questioned: some European countries also have large military programmes, and the ratio of total research and development expenditures to turnover in many European firms is as high as that of their United States competitors. There is some evidence that firms which have been heavily dependent on military work have a less satisfactory performance in exports and in the civil market. For some products at least, the scale of development work in European firms has been below the minimum 'threshold' necessary for effective competition on the world market. A high ratio of research and development expenditure can still be a low absolute figure if sales are low, and any number of firms with a scale of effort below the 'threshold' will be ineffective as they will be late in developing the new products essential for survival. Military and space programmes gave United States firms an advantage for some products where management was able to exploit and adapt the consequent experience and technique for the differing requirements of the civil market, but similar military programmes in 